small number of experts in any one area, who can easily identify each other through their arguments.

Similarly, he argued, free-flowing discussion among NEJM editors would be stemmed "if litigants were able to pick apart this internal editorial process to serve their own needs".

Scientists and editors have rallied to the NEJM's cause. Donald Kennedy, editor-in-chief of Science, calls Pfizer's efforts a "fishing expedition" because of its failure to specify what it is looking for. If Pfizer prevails, says Marcia Angell, a senior lecturer in social medicine at Harvard Medical School and a former editor of the NEJM, "it would undermine the whole system of peer review, which depends utterly on confidentiality".

Aravinda Chakravarti, a computational biologist and geneticist at Johns Hopkins University in Baltimore, Maryland, says that he can imagine "exceptional circumstances" in which a manuscript review could be submitted as part of litigation, with any potentially identifying information removed. But with Pfizer requesting all of the reviews on 11 papers and possibly more, he says: "I am worried about the precedent. This may benefit Pfizer, but science loses in a big way."

A ruling is expected on 13 March. Meredith Wadman

Nobody knows exactly where dark matter lives in the Milky Way, although it is likely to exist in our Solar System in some shape or form, according to Ben Moore, a theorist at the University of Zurich in Switzerland. But he adds that many proposed versions of the stuff would never interact with a germanium crystal - or anything else. "It's a gamble," he says. "If dark matter is one of those alternative candidates, then they're not going to see anything."

Sadoulet is the first to admit that this may be the case. Still, he hastens to add, there is good reason to look, especially because several other experiments may soon provide further clues. A satellite called the Gamma-ray Large Area Space Telescope will launch later this year, and may provide evidence of dark matter 'annihilating' in the cosmos. Also this year, the Large Hadron Collider, the world's largest particle accelerator, which is located at CERN near Geneva in Switzerland, will start looking for signals that could confirm the existence of some classes of dark-matter particle.

The risk of coming up empty-handed nags at the field, Sadoulet says. But if something is found, "it will be a new start for particle physics".

Geoff Brumfiel

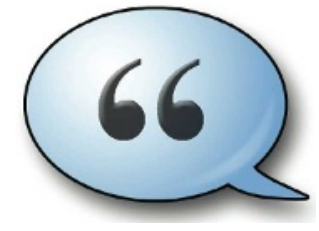

HAVE YOUR SAY

Comment on any of our news stories, online.

www.nature.com/news

\title{
Entomologists stifled by Indian bureaucracy
}

An international collaboration to study insects in the Western Ghats mountains in southern India has been unable to get off the ground because of government concerns over biopiracy.

The Indian-American project aims to sample insects from different ecosystems at various elevations, and incorporate about 200,000 specimens into national insect collections. "We have already identified 24 taxonomists from all over the world who are willing to work on this project," says Priyadarsanan Dharmarajan, a taxonomist at the Ashoka Trust for Research in Ecology and the Environment in Bangalore, who leads the Indian team.

But the project has stalled because India's National Biodiversity Authority (NBA) has denied the Ashoka Trust permission to export the specimens, despite assurances that they would be returned to India after identification. "We have to send the specimens abroad for identification as we do not have the expertise at home," Dharmarajan says.

Indian biodiversity rules guiding foreign collaborations require permission from the NBA before specimens can be exported. Under the Biological Diversity Act, specimens must not be deposited in international museums but kept only in designated repositories in India.

Now Paul Tinerella, insect collection manager at the Illinois Natural History Survey in Champaign, which is involved in the project, has informed the Ashoka Trust that the venture is "doomed" without the exit permits from the NBA or relevant supporting documents from the Indian government. "Biodiversity assessment is critical to wise land-use planning and without the basics of a sound taxonomic framework across the spectrum of life, biodiversity assessment is extremely faulty," says Michael Irwin, an insect ecologist at the Illinois Natural History Survey.

The draconian regulations on the free exchange of specimens could isolate Indian biodiversity researchers, says K. D. Prathapan, a taxonomist at the Kerala Agricultural University. "This could totally isolate Indian biodiversity researchers.” Prathapan's own recent discovery of three new species of flea beetle in India "would have been impossible" but for the loan of specimens from five international museums in four countries.

Krishnamoorthy Venkataraman, secretary of the NBA, says that the rules aim to fight biopiracy and not to stop basic research. "There is no restriction on collection or export of a few specimens for research," he told Nature. "But exporting 200,000 specimens is not permissible." The NBA encourages Indian scientists to send photographs or digital images to collaborators abroad instead of actual specimens, he says.

Dharmarajan hopes that the Indian government will follow the example of Brazil, which repealed its initially tough rules for biological specimens after protests by scientists.

K. S. Jayaraman

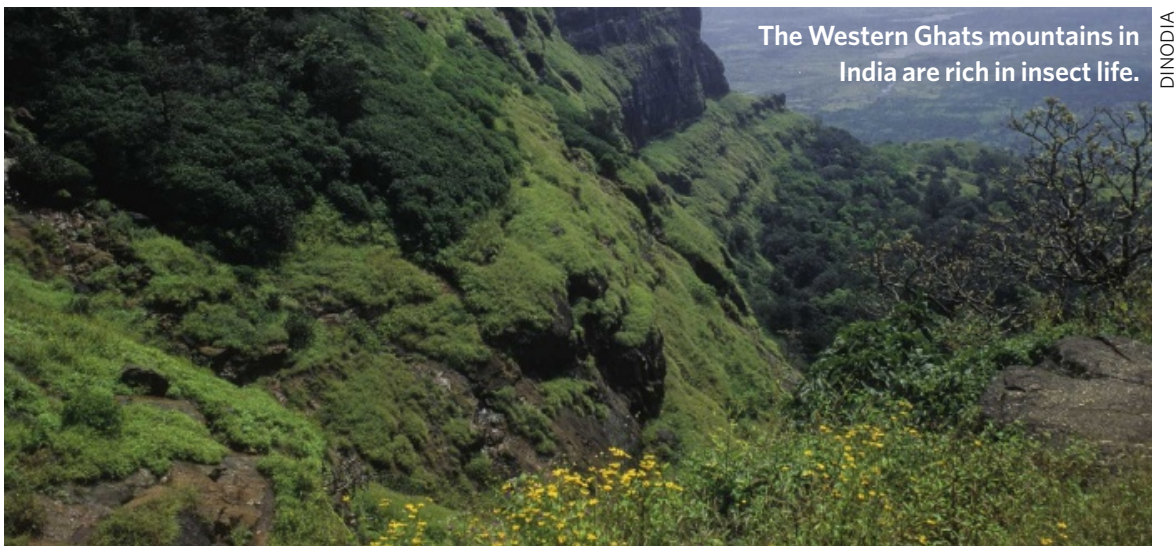

